\title{
Supplemental But Not Photoperiodic Lighting Increased Seedling Quality and Reduced Production Time of Annual Bedding Plants
}

\author{
Allison Hurt and Roberto G. Lopez ${ }^{1}$ \\ Department of Horticulture, Michigan State University, East Lansing, MI 48824 \\ Joshua K. Craver \\ Department of Horticulture and Landscape Architecture, Colorado State \\ University, Fort Collins, CO 80523
}

Additional index words. controlled-environment agriculture, light-emitting diode, LED, highpressure sodium lamps, plugs, daily light integral

\begin{abstract}
In northern latitudes, the photosynthetic daily light integral can be less than $5 \mathrm{~mol} \cdot \mathrm{m}^{-2} \cdot \mathrm{d}^{-1}$, necessitating the use of supplemental lighting (SL) to reduce bedding plant seedling production time and increase quality. Our objectives were 1) to quantify seedling quality and production time under continuous 16-h or instantaneous threshold SL, continuous lowintensity photoperiodic lighting (PL) for 16 or 24 hours with and without far-red light, or no electric lighting; and 2) to determine whether the described lighting treatments during propagation impact finished plant quality or flowering. Seeds of begonia (Begonia $\times$ semperflorens) 'Bada Bing Scarlet', gerbera (Gerbera jamesonii) 'Jaguar Deep Orange', impatiens (Impatiens walleriana) 'Accent Premium Salmon', petunia (Petunia $\times$ hybrida) 'Ramblin Peach Glo', and tuberous begonia (Begonia $\times$ tuberosa) 'Nonstop Rose Petticoat' were sown in 128-cell trays and grown under either SL, PL, or no electric lighting (control). SL treatments consisted of high-intensity light-emitting diode (LED) or high-pressure sodium (HPS) lamps providing a photosynthetic photon flux density $(P P F D)$ of either $70 \mu \mathrm{mol} \cdot \mathrm{m}^{-2} \cdot \mathrm{s}^{-1}$ on continuously for $16 \mathrm{~h}^{-1}$ or $90 \mu \mathrm{mol} \cdot \mathrm{m}^{-2} \cdot \mathrm{s}^{-1}$ based on an instantaneous threshold. PL treatments consisted of low-intensity

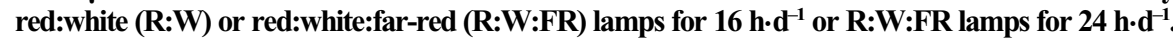
Seedlings of gerbera, impatiens, and petunia from each treatment were subsequently transplanted and finished in a common greenhouse environment. The highest quality seedlings were grown under SL compared with PL or control conditions. When comparing SL treatments, seedlings produced under HPS or LED SL using an instantaneous threshold were of equal or greater quality compared with those under continuous SL with a 16-h photoperiod. Although the greater leaf area and internode elongation under PL may give growers the perception that seedling production time is reduced, PL did not increase biomass accumulation and seedling quality. Petunia seedlings propagated under HPS lamps using an instantaneous threshold flowered 4 to 11 days earlier compared with the other SL treatments. In addition, petunia propagated under R:W:FR PL for 16 $h \cdot d^{-1}$ flowered 5 to 7 days earlier compared with LED SL and the other PL treatments.
\end{abstract}

Seed propagation of bedding plants for spring markets commonly begins during the late winter months, when the greenhouse photosynthetic daily light integral (DLI) in

Received for publication 15 Oct. 2018. Accepted for publication 3 Dec. 2018.

This work was supported by the U.S. Department of Agriculture (USDA) National Institute of Food and Agriculture, Hatch project MICL02472.

We gratefully acknowledge support by the USDA-Agricultural Research Service Floriculture and Nursery Research Initiative, Philips Lighting, Hort Americas, The Western Michigan Greenhouse Association, and The Metro Detroit Flower Growers Association for funding; Ball Horticultural Co. for seeds; Raker-Roberta's for plant material; The Blackmore Company for fertilizer; and Nathan DuRussel for technical assistance.

The use of trade names in this publication does not imply endorsement by Michigan State University or Colorado State University of products named nor criticism of similar ones not mentioned.

${ }^{1}$ Corresponding author. E-mail: rglopez@msu.edu. lamps on and off is instantaneous, and devices can be integrated easily into digital control systems for the manipulation of lighting duration and intensity (Morrow, 2008). For SL applications, the capability to control on/off cycles via quantum sensors and an established intensity threshold provides growers with greater electrical energy savings by not supplying SL to a crop when ambient levels in the greenhouse are deemed sufficient for plant growth. Thus, LED technology may provide substantial benefits over conventional lamps for SL, because advancements in sensors and control systems allow for more precise management of the light environment.

Because LEDs can be designed to provide a variety of narrow and broad wave bands, specific morphological or physiological responses in a crop can be targeted by adjusting the spectrum emitted by the lamps (Both et al., 2017; Massa et al., 2008). For example, Hernández and Kubota (2016) found that as the percentage of blue light provided by red:blue LEDs increased (up to $75 \%)$ at a light intensity of $100 \mu \mathrm{mol} \cdot \mathrm{m}^{-2} \cdot \mathrm{s}^{-1}$, seedlings of cucumber (Cucumis sativus) 'Cumlaude' displayed shorter hypocotyls and a smaller leaf area. Similar responses have been observed with bedding plant seedlings produced under sole-source LED lighting; seedlings grown under sufficient intensities of blue light $\left(\geq 10 \mu \mathrm{mol} \cdot \mathrm{m}^{-2} \cdot \mathrm{s}^{-1}\right)$ were often more compact and of higher quality (Randall and Lopez, 2014, 2015; Wollaeger and Runkle, 2015). Although many such responses have been observed under solesource lighting environments, the benefit of spectrum manipulation for SL in the greenhouse remains uncertain.

When natural day lengths are short (e.g., $<13 \mathrm{~h}$ ), PL is commonly used in greenhouse environments to initiate or accelerate flowering for species with a long-day photoperiodic response (Craig and Runkle, 2012; Mattson and Erwin, 2005). Conversely, PL can be used for species with a short-day photoperiodic response to maintain a vegetative state. Traditionally, PL has been delivered by incandescent, halogen, or compact fluorescent lamps at a low intensity $\left(1-2 \mu \mathrm{mol} \cdot \mathrm{m}^{-2} \cdot \mathrm{s}^{-1}\right)$ primarily consisting of red $(600-700 \mathrm{~nm})$ and far-red (700-800 nm) wavelengths (Runkle and Both, 2017). More recently, low-intensity LED lamps have become an alternative because of their increased electrical efficacy, longer life span, and ability to manipulate spectral quality (Craig and Runkle, 2012; Morrow, 2008).

In recent years, some young plant propagators in northern latitudes have installed low-intensity LED lamps to extend the photoperiod to 16 to $24 \mathrm{~h}$ in an attempt to improve growth and development. Although this low-intensity photoperiodic lighting contributes very little to the cumulative DLI, some growers have reported that timing of both rooted cuttings (liners) and seedlings (plugs) is reduced compared with those provided no electric lighting (Sparks, 2016). Although the perceived increase in seedling quality is likely unrelated to increased 
biomass resulting from the low contribution of PL to DLI, impacts to seedling morphology may be present. For example, FR wavelengths are often emitted from PL lamps as a result of their role in flowering for species with a long-day photoperiodic response. However, FR light has also been shown to manipulate shade avoidance symptoms in many species, often characterized by increased stem elongation and leaf area expansion (Franklin and Whitelam, 2005; Park and Runkle, 2017). Therefore, although biomass may be unaffected, responses such increased leaf area under PL may be perceived as increased growth.

Although previous research has assessed the use of LEDs for greenhouse SL, to our knowledge, no detailed research has been conducted to evaluate the benefits of cycling LEDs using an instantaneous intensity threshold. In addition, with the release of new PL lamps, confusion still exists among growers regarding the benefits of PL beyond initiating, accelerating, or delaying flowering responses in photoperiod-sensitive species. Therefore, the objectives of our study were 1) to quantify seedling quality and production time of five commercially important species under continuous 16-h or instantaneous threshold SL, continuous low-intensity LED PL for 16 or $24 \mathrm{~h}$ with and without far-red light, or no electric lighting; and 2) to determine whether the described lighting treatments during propagation affect finished plant quality or flowering in a common finishing environment.

\section{Materials and Methods}

Plant material and propagation environment. Seeds of begonia (Begonia ×semperflorens) 'Bada Bing Scarlet', gerbera (Gerbera jamesonii) 'Jaguar Deep Orange', impatiens (Impatiens walleriana) 'Accent Premium Salmon', petunia (Petunia $\times$ hybrida) 'Ramblin Peach Glo', and tuberous begonia (Begonia $\times$ tuberosa) 'Nonstop Rose Petticoat' were sown into 128-cell trays $(2.7 \times 2.7 \mathrm{~cm} ; 12.0-\mathrm{mL}$ individual cell volume) at a commercial greenhouse (Raker-Roberta's, Litchfield, MI). Upon hypocotyl emergence, plug trays of each species were placed under lighting treatments in the Plant Science Research Greenhouse ranges at Michigan State University (East Lansing, MI; lat. $42^{\circ} \mathrm{N}$ ). Seedlings were irrigated as needed with reverse-osmosis water supplemented with water-soluble fertilizer (MSU Plug Special; GreenCare Fertilizers, Inc., Kankakee, IL) providing $\left(\mathrm{mg} \cdot \mathrm{L}^{-1}\right) 60$ nitrogen $(\mathrm{N}), 23$ phosphorus (P), 60 potassium $(\mathrm{K}), 27.7$ calcium $(\mathrm{Ca}), 4.6$ magnesium $(\mathrm{Mg}), 1.3$ iron $(\mathrm{Fe}), 0.6$ manganese $(\mathrm{Mn}), 0.6$ zinc $(\mathrm{Zn}), 0.6$ copper $(\mathrm{Cu}), 0.4$ boron (B), and 0.1 molybdenum (Mo).

All species were grown in an east-to-westoriented glass-glazed greenhouse, with an environmental computer (Integro 725; Priva North America, Vineland, Ontario, Canada) that controlled exhaust fans, ridge vents, evaporative pad cooling, radiant hot-water heating, and steam injection to maintain a vapor pressure deficit of $0.3 \mathrm{kPa}$ and an air temperature set point of $22{ }^{\circ} \mathrm{C}$. Whitewash
(ReduSol; Mardenkro, Baarle-Nassau, Netherlands) was applied on the exterior south side of the greenhouse during the second and third replications to decrease the light intensity (by $\approx 25 \%$ to $40 \%$ ) and improve the uniformity of sunlight between replications. Under each treatment, light intensity at crop height was recorded by a quantum sensor (LI-190SA; LI-COR, Lincoln, NE), canopy air temperature by an aspirated tube containing a thermocouple (Type E; Omega Engineering, Stamford, $\mathrm{CT}$ ), and leaf canopy temperature by infrared sensors (Type K, OS36-01; Omega Engineering) placed $3 \mathrm{~cm}$ above the leaf canopy and oriented downward at a $45^{\circ}$ angle. Environmental data under each lighting treatment were measured every $10 \mathrm{~s}$, and hourly averages were logged with a data logger (CR1000; Campbell Scientific, Logan, UT). Environmental data are reported in Table 1.

Supplemental and photoperiodic lighting treatments. One tray of each species was placed under one of eight lighting treatments for $28 \mathrm{~d}$ (gerbera, impatiens, and petunia) or $42 \mathrm{~d}$ (begonia and tuberous begonia). Lighting treatments included a natural daylength with no electric lighting (control; natural light), four SL, and three PL treatments. SL treatments were delivered by 200-W LED (LED_70) (Philips GP-TOPlight DRW-MB; Koninklijke Philips N.V., Eindhoven, Netherlands) or 400-W HPS lamps (HPS_70) (LR48877; P.L. Light Systems, Beamsville, Ontario, Canada) providing a $P P F D$ of 70 $\mu \mathrm{mol} \cdot \mathrm{m}^{-2} \cdot \mathrm{s}^{-1}$ (on continuously for $16 \mathrm{~h} \cdot \mathrm{d}^{-1}$ from 0600 to $2200 \mathrm{HR}$ ), or LED (LED_90) or HPS lamps (HPS_90) providing a PPFD of $90 \mu \mathrm{mol} \cdot \mathrm{m}^{-2} \cdot \mathrm{s}^{-1}$ based on an instantaneous threshold [on from 0600 to $2200 \mathrm{HR}$ when the outside PPFD was less than $\approx 440 \mu \mathrm{mol} \cdot \mathrm{m}^{-2} \cdot \mathrm{s}^{-1}$ (on for a minimum of $25 \mathrm{~min}$ and off for a minimum of $20 \mathrm{~min}$ )]. The 100-nm waveband ratios (measured as a percentage of the LED and HPS lamps, defined by their blue $(400-500 \mathrm{~nm})$, green $(500-600 \mathrm{~nm})$, and red $(600-700 \mathrm{~nm})$ photon flux densities, were 10:5:85 and 6:61:33, respectively. Each LED lamp (122 cm long, $5 \mathrm{~cm}$ wide, and $10 \mathrm{~cm}$ tall) contained one array containing 200 diodes (162 red, 24 white, and 14 blue). All lamps for supplemental treatments were placed $163 \mathrm{~cm}$ above the benches, with the exception of HPS lamps providing $90 \mu \mathrm{mol} \cdot \mathrm{m}^{-2} \cdot \mathrm{s}^{-1}$, which were placed at $123 \mathrm{~cm}$ to increase the light intensity.

Photoperiodic lighting treatments consisted of 15-W flowering lamps (GreenPower LED flowering lamp, DR:W $120 \mathrm{~V}$, E26; Philips) containing red and white LEDs (R: $\mathrm{W})$ on for $16 \mathrm{~h} \cdot \mathrm{d}^{-1}\left(\mathrm{R}: \mathrm{W} \_16\right)$ from 0600 to $2200 \mathrm{HR}$, or 10-W flowering lamps (Arize Greenhouse Pro photoperiodic LED Lamp; GE Lighting, Cleveland, $\mathrm{OH}$ ) containing blue, white, red, and far-red LEDs on for $16 \mathrm{~h} \cdot \mathrm{d}^{-1}$ (R:W:FR_16) or $24 \mathrm{~h} \cdot \mathrm{d}^{-1}$ (R:W:FR_24). The $100-\mathrm{nm}$ waveband ratios (measured as a percentage of the R:W and R:W:FR LED lamps, defined by their blue, green, red, and far-red photon flux densities, were 6:14:78:2 and 3:17:48:32, respectively. All lamps for PL treatments were placed $86.5 \mathrm{~cm}$ above the benches. A flexible and neutral-density metal mesh (General Purpose Aluminum; New York Wire, Grand Island, NY) was placed over all photoperiodic and supplemental LED lamps as needed to reduce light intensity to the desired level. The spectral distribution of the SL and PL treatments was measured using a spectroradiometer (PS-200; StellarNet, Inc., Tampa, FL) in six representative locations under each lamp (Fig. 1).

Finishing culture and environment. After $28 \mathrm{~d}$ under propagation lighting treatments, 10 randomly selected impatiens and petunia seedlings from each treatment were transplanted into $11.5-\mathrm{cm}$-round containers, and gerbera seedlings were transplanted in 10.2cm-round containers (Injection Molded Pot; Dillen Products Inc., Middlefield, $\mathrm{OH}$ ) filled with a soilless medium comprised of $70 \%$ peat, $21 \%$ perlite, and 9\% vermiculite (Suremix; Michigan Grower Products Inc., Galesburg, MI). Plants were placed in a common finishing environment with a $16 \mathrm{~h} \cdot \mathrm{d}^{-1}$ photoperiod of ambient light supplemented with a $P P F D$ of $70 \mu \mathrm{mol} \cdot \mathrm{m}^{-2} \cdot \mathrm{s}^{-1}$ from the same high-intensity LED (impatiens and petunia) or HPS (gerbera) lamps used in propagation. The average air temperature and DLI $( \pm \mathrm{SD})$ in the finishing environments over the three replications was $20.2 \pm 1.4{ }^{\circ} \mathrm{C}$ and $11.4 \pm$ $1.9 \mathrm{~mol} \cdot \mathrm{m}^{-2} \cdot \mathrm{d}^{-1}$ for petunia and impatiens, and $22.8 \pm 2.3{ }^{\circ} \mathrm{C}$ and $12.4 \pm 2.2 \mathrm{~mol} \cdot \mathrm{m}^{-2} \cdot \mathrm{d}^{-1}$ for gerbera. Plants were irrigated as needed with reverse-osmosis water supplemented with water-soluble fertilizer (MSU Orchid RO Water Special; GreenCare Fertilizers, Inc., Kankakee, IL) providing $\left(\mathrm{mg} \cdot \mathrm{L}^{-1}\right) 125$ $\mathrm{N}, 12 \mathrm{P}, 100 \mathrm{~K}, 65 \mathrm{Ca}, 12 \mathrm{Mg}, 1.0 \mathrm{Fe}, 1.0 \mathrm{Cu}$, $0.5 \mathrm{Mn}, 0.5 \mathrm{Zn}, 0.3 \mathrm{~B}$, and $0.1 \mathrm{Mo}$.

Data collection and calculations. At $28 \mathrm{~d}$ (petunia, impatiens, and gerbera) or $42 \mathrm{~d}$ (begonia and tuberous begonia) under lighting treatments, five seedlings of each species were selected randomly to measure stem length (from the base of the hypocotyl to the shoot apical meristem) and stem diameter (at the base of the hypocotyl) using a digital caliper (DigiMax; Wiha Tools; Switzerland). After nondestructive measurements, leaf number was recorded, and leaf area was determined for petunia and impatiens using a leaf area meter (LI-3000, LI-COR). Roots and shoots of all selected seedlings were washed and separated, placed in a drying oven at $95{ }^{\circ} \mathrm{C}$ for at least $4 \mathrm{~d}$, and root dry mass and shoot dry mass (stem and leaves) were recorded. The sturdiness quotient (SQ) was calculated as stem caliper divided by stem length. The quality index (QI), an objective, integrated, and quantitative measurement of floriculture plug quality, was calculated as [total dry mass $\times$ (shoot:root ratio + SQ)] (Currey et al., 2013).

After transplant, plants were checked daily to record time to visible bud and time to first open flower (TTF). At first flower, plant width, height, and number of flower buds were recorded for all species. Nodes to first flower were also recorded for petunia and impatiens, and leaf number was recorded for gerbera. 
Table 1. Average ( $\pm \mathrm{SD})$ daily light integral, leaf temperature, canopy air temperature, and total hours of operation for supplemental and photoperiodic lighting sources logged every hour by a data logger (model CR1000; Campbell Scientific, Logan, UT). Data were collected under continuous supplemental lighting with a 16-h photoperiod provided by high-pressure sodium (HPS_70) or light-emitting diode (LED_70) lamps at a photosynthetic photon flux density (PPFD) of $70 \mu \mathrm{mol} \cdot \mathrm{m}^{-2} \cdot \mathrm{s}^{-1}$; supplemental lighting based on an instantaneous threshold (on from 0600 to $2200 \mathrm{HR}$ when outside $P P F D$ was less than $\approx 440 \mu \mathrm{mol} \cdot \mathrm{m}^{-2} \cdot \mathrm{s}^{-1}$ ) provided by HPS (HPS_90) or LED (LED_90) lamps at a PPFD of $90 \mu \mathrm{mol} \cdot \mathrm{m}^{-2} \cdot \mathrm{s}^{-1}$; photoperiodic lighting provided by 15 -W red:white flowering lamps with a 16-h photoperiod (R:W_16), 10-W red:white:far-red flowering lamps with a 16-h photoperiod (R:W:FR_16), or 10-W red:white:far-red flowering lamps with a 24-h photoperiod (R:W:FR_24); or no supplemental or photoperiodic lighting (Natural). Means values reported were averaged for each replication (Rep) of the experiment over time.

\begin{tabular}{|c|c|c|c|c|c|c|c|c|}
\hline Rep & Natural & HPS_70 & HPS_90 & LED_70 & LED_90 & $\mathrm{R}: \mathrm{W} \_16$ & R:W:FR_16 & R:W:FR_24 \\
\hline & \multicolumn{8}{|c|}{ Daily light integral $\left(\mathrm{mol} \cdot \mathrm{m}^{-2} \cdot \mathrm{d}^{-1}\right)$} \\
\hline 2 & $5.3 \pm 4.1$ & $9.9 \pm 4.1$ & $10.1 \pm 4.0$ & $9.7 \pm 4.3$ & $11.3 \pm 4.3$ & $5.7 \pm 4.3$ & $5.6 \pm 4.1$ & $6.0 \pm 4.5$ \\
\hline 1 & $22.7 \pm 1.0$ & $24.4 \pm 1.1$ & $24.5 \pm 1.4$ & $23.9 \pm 1.4$ & $23.0 \pm 1.1$ & $23.3 \pm 1.1$ & $23.5 \pm 1.1$ & $23.5 \pm 1.0$ \\
\hline 2 & $22.3 \pm 0.9$ & $24.4 \pm 1.4$ & $24.2 \pm 1.3$ & $23.5 \pm 1.3$ & $23.4 \pm 1.2$ & $23.3 \pm 1.2$ & $23.7 \pm 1.0$ & $23.1 \pm 1.2$ \\
\hline 3 & $22.5 \pm 1.5$ & $23.9 \pm 1.7$ & $24.1 \pm 1.6$ & $23.1 \pm 1.5$ & $23.5 \pm 1.4$ & $23.3 \pm 1.6$ & $23.6 \pm 1.6$ & $23.2 \pm 1.4$ \\
\hline 2 & $22.0 \pm 1.3$ & $23.1 \pm 1.2$ & $22.7 \pm 1.3$ & $22.5 \pm 1.2$ & $22.6 \pm 1.1$ & $23.0 \pm 1.2$ & $23.2 \pm 1.3$ & $23.0 \pm 1.2$ \\
\hline \multirow[t]{2}{*}{3} & $22.8 \pm 1.6$ & $23.1 \pm 1.7$ & $23.5 \pm 1.7$ & $22.2 \pm 1.6$ & $22.6 \pm 1.6$ & $22.7 \pm 1.6$ & $22.8 \pm 1.7$ & $22.8 \pm 1.6$ \\
\hline & \multicolumn{8}{|c|}{ Total hours of operation } \\
\hline 1 & 0 & 447 & 357 & 438 & 357 & 448 & 448 & 672 \\
\hline 2 & 0 & 448 & 403 & 448 & 403 & 448 & 448 & 672 \\
\hline 3 & 0 & 447 & 319 & 447 & 319 & 448 & 448 & 672 \\
\hline
\end{tabular}

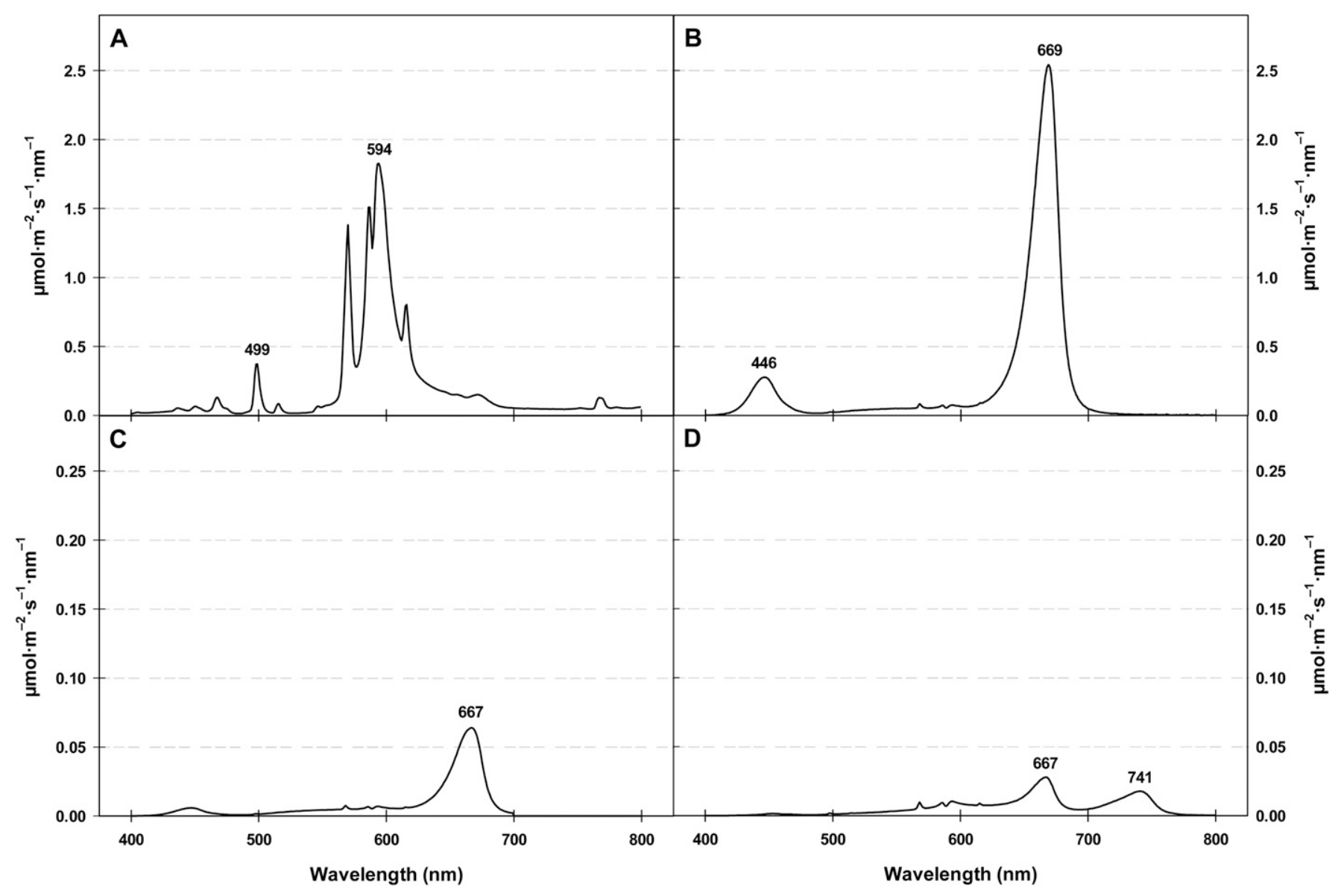

Fig. 1. Spectral quality delivered from high-intensity 400-W high-pressure sodium lamps (A) or 200-W light-emitting diode lamps (B) at a photosynthetic photon flux density $(P P F D)$ from $400-700 \mathrm{~nm}$ of $90 \mu \mathrm{mol} \cdot \mathrm{m}^{-2} \cdot \mathrm{s}^{-1}, 15-\mathrm{W}$ red:white $(\mathbf{C})$, or 10-W red:white:far-red (D) flowering lamps at a $P P F D$ of $2 \mu \mathrm{mol} \cdot \mathrm{m}^{-2} \cdot \mathrm{s}^{-1}$ at canopy level.

Statistical analysis. This experiment used a randomized complete block design with subsamples, and was performed three times during the peak commercial propagation season (December-March), with seeds sown in Nov. 2016 and Jan. and Feb. 2017. Treatment effects for both propagation and finishing were compared by analysis of variance using SAS (version 9.4; SAS Institute, Cary, NC) PROC MIXED and Tukey's honestly significant difference test at $P \leq 0.05$ to provide pairwise comparisons between treatments.

\section{Results}

Propagation. Stem length of impatiens and petunia seedlings was generally shorter under SL compared with PL and natural light (Fig. 2A). In addition, stem length of gerbera, 


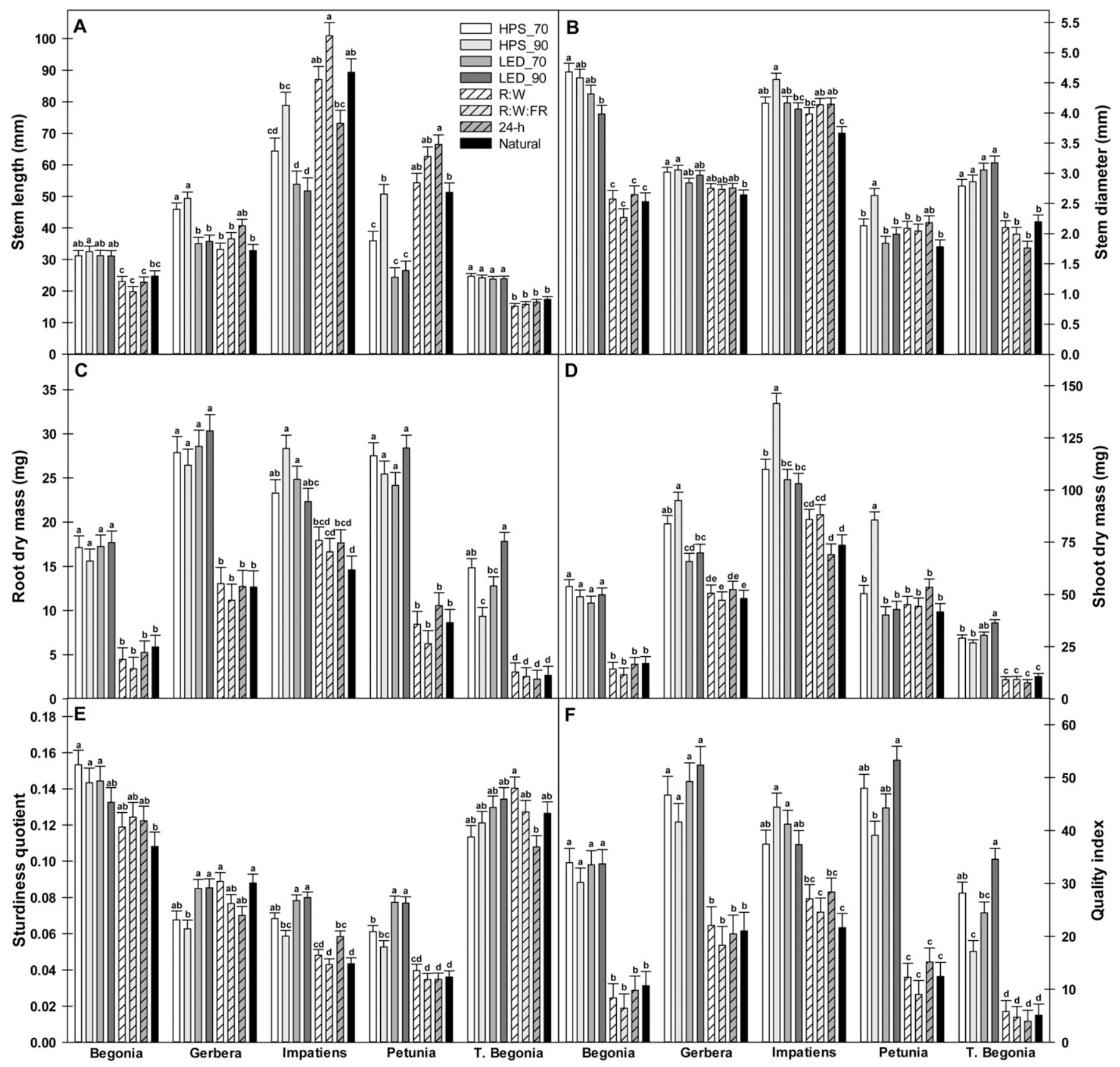

Fig. 2. Stem length (A), stem diameter (B), root dry mass (C), shoot dry mass (D), sturdiness quotient (E), and quality index (F) for begonia, gerbera, impatiens, petunia, and tuberous begonia seedlings collected 42,28,28,28, and $42 \mathrm{~d}$ after germination, respectively, grown under continuous supplemental lighting with a 16-h photoperiod provided by high-pressure sodium (HPS_70) or light-emitting diode (LED_70) lamps at a photosynthetic photon flux density (PPFD) of 70 $\mu \mathrm{mol} \cdot \mathrm{m}^{-2} \cdot \mathrm{s}^{-1}$; supplemental lighting based on an instantaneous threshold (on from 0600 to $0800 \mathrm{HR}$ and 1700 to $2200 \mathrm{HR}$, and on between 0800 and $1700 \mathrm{HR}$ when outside $P P F D$ was less than $\approx 440 \mu \mathrm{mol} \cdot \mathrm{m}^{-2} \cdot \mathrm{s}^{-1}$ ) provided by HPS (HPS_90) or LED (LED_90) lamps at a PPFD of $90 \mu \mathrm{mol} \cdot \mathrm{m}^{-2} \cdot \mathrm{s}^{-1} ; \mathrm{photoperiodic}$ lighting provided by $15-\mathrm{W}$ red:white flowering lamps with a 16-h photoperiod (R:W), $10-\mathrm{W}$ red:white:far-red flowering lamps with a 16-h photoperiod (R:W: FR), or 10-W red:white:far-red flowering lamps with a 24-h photoperiod (24-h); or no supplemental or photoperiodic lighting (Natural). Means sharing a letter are not statistically different by Tukey's honestly significant difference test at $P \leq 0.05$.

impatiens, and petunia was shortest under SL from LED compared with HPS lamps. For example, stem length of gerbera was $24 \%$ shorter under LED_70 compared with HPS_70. In addition, stem length of gerbera, impatiens, and petunia was $28 \%, 34 \%$, and 48\% shorter under LED_90 compared with HPS_90, respectively. Although no differences between SL treatments were observed for begonia and tuberous begonia, stem length was shorter under PL compared with SL. Stem length of petunia was also $23 \%$ shorter under natural light compared with $\mathrm{R}$ : W:FR 24, whereas stem length of impatiens was $28 \%$ shorter under R:W:FR_24 compared with R:W:FR_16.

Stem diameter was generally smallest under natural light compared with SL for all species (Fig. 2B). In addition, for begonia and tuberous begonia, stem diameter was larger under SL compared with PL. Although there were few differences between SL treatments, stem diameter for petunia was $24 \%$ to $44 \%$ larger under HPS_90 compared with all other
SL treatments. In addition, although there were no differences between PL treatments for any of the species, stem diameter for impatiens was 13\% larger under R:W:FR_16 and $\mathrm{R}: \mathrm{W}: F R \_24$ compared with natural light.

In general, both root dry mass and shoot dry mass were greatest under SL compared with PL and natural light for all species (Fig. 2C and D). SL treatment responses for biomass accumulation varied among species. For example, root dry mass of tuberous begonia was $91 \%$ and $39 \%$ greater under 
LED_90 compared with HPS_90 and LED_70, respectively. Shoot dry mass of gerbera was $27 \%$ greater under HPS_70 compared with LED_70 and 36\% greater under HPS_90 compared with LED_90. Similarly, shoot dry mass of impatiens was $29 \%$ to $37 \%$ greater and shoot dry mass of petunia was $70 \%$ to $113 \%$ greater under HPS_90 compared with all other SL treatments. However, no differences between PL treatments were observed for any species.

Leaf area of both impatiens and petunia was smaller under LED compared with HPS SL (Fig. 3A). For example, leaf area of impatiens under HPS_90 was 58\% and 81\% larger compared with LED_70 and LED_90, respectively. Similarly, leaf area of petunia under HPS_90 was 176\% and 146\% larger compared with LED_70 and LED_90, respectively. Leaf area of both impatiens and petunia was also $59 \%$ and $83 \%$ larger, respectively, under HPS_90 compared with HPS_70. In addition, leaf area was often larger under PL compared with SL for both species (Fig. 3A). For example, leaf area of impatiens was $44 \%$ to $65 \%$ larger under R: W 16 and $45 \%$ to $66 \%$ larger under R:W: FR_16 compared with HPS_70, LED_70, and LED_90. Similarly, leaf area of petunia was $44 \%$ to $116 \%$ larger under R:W_16, $45 \%$ to $118 \%$ larger under R:W:FR_16, and $61 \%$ to $142 \%$ larger under R:W:FR_24 compared with HPS_70, LED_70, and LED_90. Although no differences in leaf area between PL treatments were observed for petunia, leaf area of impatiens was $33 \%$ and $34 \%$ larger under R:W_16 and R:W:FR_16, respectively, compared with R:W:FR_24.

Leaf number was generally greatest under SL compared with PL and natural light (Fig. 3B). In addition, for both impatiens and petunia, the number of leaves was greatest under HPS compared with LED SL, with similar trends to those observed for leaf area. Although no differences in leaf number were observed among PL treatments for petunia, leaf number for impatiens was greatest under R:W_16, with $29 \%$ more leaves compared with R:W:FR_24.

In general, both the SQ and QI of all species were greater under SL compared with PL and natural light (Fig. 2E and F). In addition, for gerbera, impatiens, and petunia, the SQ was greater under LED compared with HPS SL. Specifically, the SQ of petunia was 33\% greater under LED_70 compared with HPS_70. In addition, the SQ of gerbera, impatiens, and petunia was $50 \%, 33 \%$, and $60 \%$ greater, respectively, under LED_90 compared with HPS_90. Similarly, the QI of petunia and tuberous begonia was $36 \%$ and $102 \%$ greater, respectively, under LED_90 compared with HPS_90. For impatiens, the SQ was $36 \%$ and $35 \%$ greater under R:W: FR_24 compared with R:W:FR_16 and natural light, respectively. However, no differences in QI were observed among PL treatments for any of the species.

Finishing. Although no differences were present between HPS and LED SL, impatiens reached visible bud and flowered earlier when propagated under SL compared with PL or natural light (Fig. 4A and B). Specifically, impatiens propagated under SL flowered an average of 6 to $12 \mathrm{~d}$ earlier compared with those under PL or natural light. Petunia flowered earliest when propagated under HPS_90, with plants flowering an average of 4 to $11 \mathrm{~d}$ earlier compared with all other SL treatments. A decrease in TTF was also observed for petunia propagated under R:W: FR_16, with plants flowering an average of 5 to $7 \mathrm{~d}$ earlier compared with LED_70, LED_90, R:W_16, and natural light.

Petunia under SL often had fewer nodes at flowering than those under PL (Fig. 4C). For example, petunia had approximately two to three fewer nodes at flowering under LED_70 compared with R:W_16, R:W:FR_16, and R: W:FR_24. Similarly, the number of buds at flowering was fewer for impatiens prop- agated under SL compared with PL (Fig. 4D). For example, impatiens had $\approx 35$ to 40 fewer buds under HPS_70 compared with R:W_16, R:W:FR_16, and R:W:FR_24. Regarding SL, petunia had 10 fewer buds at flowering under HPS_90 compared with those under both LED_70 and LED_90. In addition, petunia had about six fewer buds at flowering under R:W:FR_16 compared with LED_70.

For impatiens, plant width at flowering was $42 \%$ and $48 \%$ greater under HPS_90 compared with HPS_70 and LED_70, respectively (Fig. 4E). Conversely, plant width of petunia at flowering was $32 \%$ and $33 \%$ smaller under HPS_90 compared with LED_70 and LED_90, respectively. Although no differences in plant height at flowering were observed for gerbera or impatiens, petunia seedlings propagated under SL were generally shorter than those propagated under PL (Fig. 4F).

\section{Discussion}

A high-quality plug is generally described as having a compact habit, thick stem diameter, reduced leaf area, and high root and shoot biomass (Oh et al., 2010; Pramuk and Runkle, 2005; Randall and Lopez, 2014). These quality attributes are highly desired by growers because they facilitate processing, shipping, and transplanting (Pramuk and Runkle, 2005). In the present study, impatiens and petunia seedlings grown under SL generally had less stem elongation and increased stem diameter compared with those grown under no SL. Under low-light environments, many species will exhibit the shade avoidance response, during which stems elongate to breach a perceived canopy (Franklin, 2008). In our study, the average DLI achieved under natural light was as low as $4.8 \mathrm{~mol} \cdot \mathrm{m}^{-2} \cdot \mathrm{d}^{-1}$, which is considerably less than the recommended target of 10 to

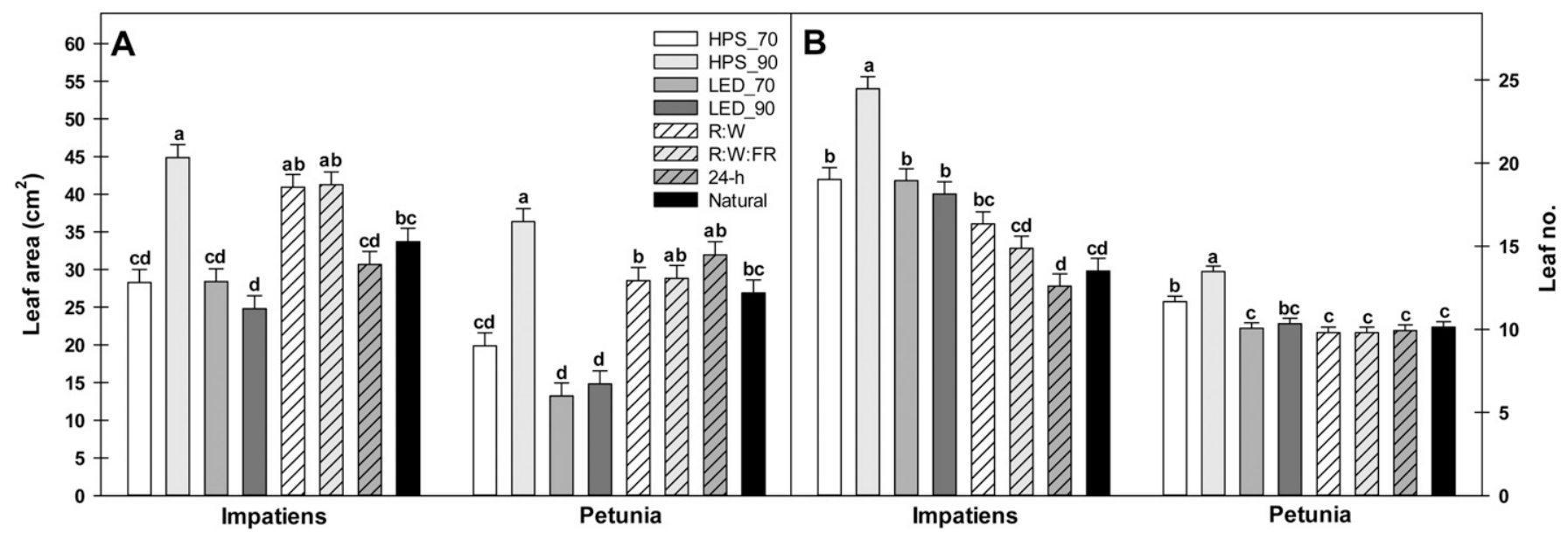

Fig. 3. Leaf area (A) and number (B) for impatiens and petunia seedlings collected $28 \mathrm{~d}$ after germination grown under continuous supplemental lighting with a 16$\mathrm{h}$ photoperiod provided by high-pressure sodium (HPS 70) or light-emitting diode (LED 70) lamps at a photosynthetic photon flux density (PPFD) of 70 $\mu \mathrm{mol} \cdot \mathrm{m}^{-2} \cdot \mathrm{s}^{-1}$; supplemental lighting based on an instantaneous threshold (on from 0600 to $0800 \mathrm{HR}$ and 1700 to $2200 \mathrm{HR}$, and on between $0800 \mathrm{and} 1700 \mathrm{HR}$ when outside $P P F D$ was less than $\approx 440 \mu \mathrm{mol} \cdot \mathrm{m}^{-2} \cdot \mathrm{s}^{-1}$ ) provided by HPS (HPS_90) or LED (LED_90) lamps at a PPFD of $90 \mu \mathrm{mol} \cdot \mathrm{m}^{-2} \cdot \mathrm{s}^{-1} ; \mathrm{photoperiodic}$ lighting provided by either $15-\mathrm{W}$ red:white flowering lamps with a 16-h photoperiod (R:W), 10-W red:white:far-red flowering lamps with a 16-h photoperiod (R:W:FR), or 10-W red:white:far-red flowering lamps with a 24-h photoperiod (24-h); or no supplemental or photoperiodic lighting (Natural). Means sharing a letter are not statistically different by Tukey's honestly significant difference test at $P \leq 0.05$. 


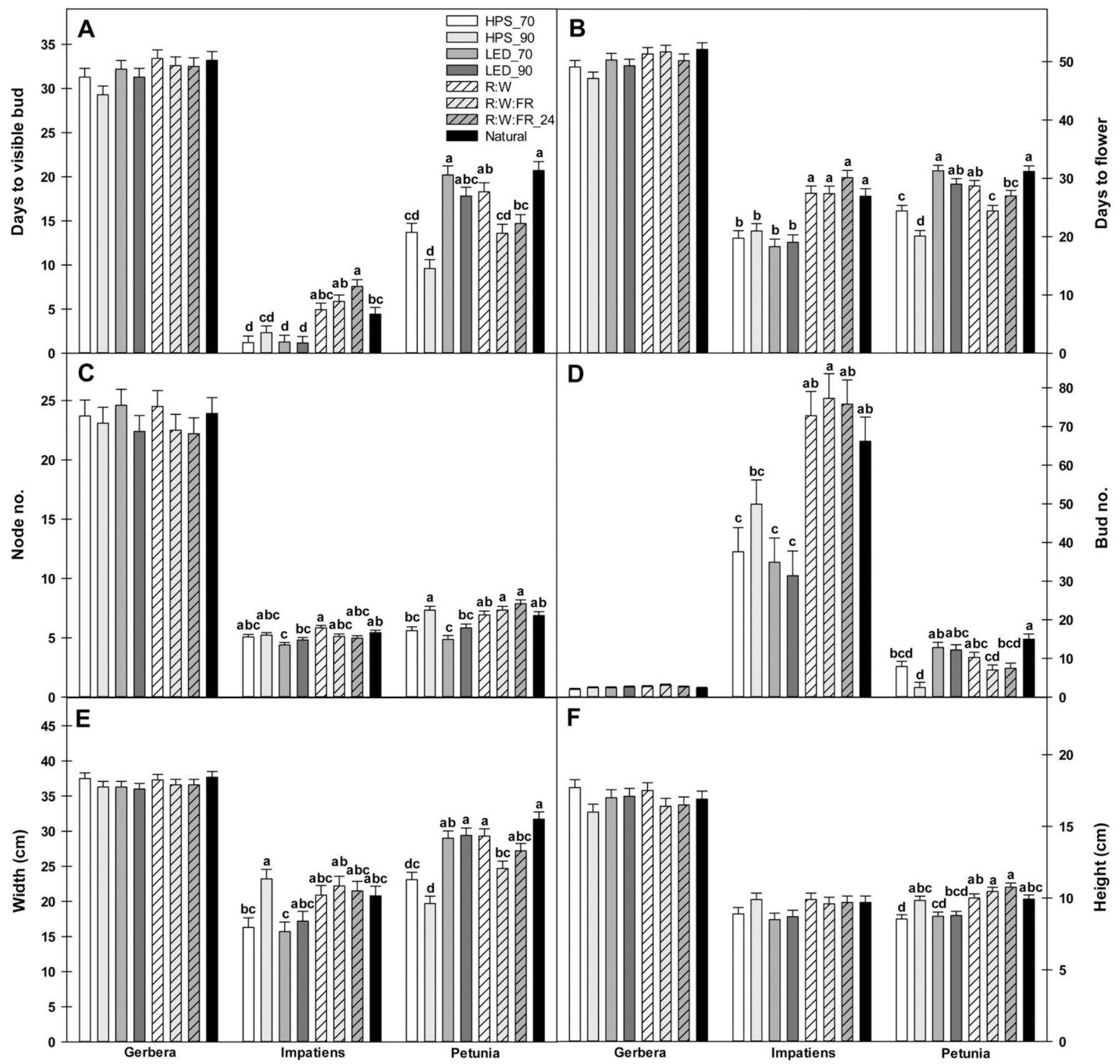

Fig. 4. Days to visible bud (A), days to flower $(\mathbf{B})$, node number $(\mathbf{C})$, bud number $(\mathbf{D})$, width $(\mathbf{E})$, and height $(\mathbf{F})$ at finishing for gerbera, impatiens, and petunia seedlings propagated under continuous supplemental lighting with a 16-h photoperiod provided by high-pressure sodium (HPS_70) or light-emitting diode (LED_70) lamps at a photon flux density (PPFD) of $70 \mu \mathrm{mol} \cdot \mathrm{m}^{-2} \cdot \mathrm{s}^{-1}$; supplemental lighting based on an instantaneous threshold (on from 0600 to $0800 \mathrm{HR}$ and 1700 to $2200 \mathrm{HR}$, and on between 0800 and $1700 \mathrm{HR}$ when outside $P P F D$ was less than $\approx 440 \mu \mathrm{mol} \cdot \mathrm{m}^{-2} \cdot \mathrm{s}^{-1}$ ) provided by HPS (HPS_90) or LED (LED_90) lamps at a $P P F D$ of $90 \mu \mathrm{mol} \cdot \mathrm{m}^{-2} \cdot \mathrm{s}^{-1}$; photoperiodic lighting provided by either $15-\mathrm{W}$ red:white flowering lamps with a 16-h photoperiod (R:W), 10-W red:white:farred flowering lamps with a 16-h photoperiod (R:W:FR), or 10-W red:white:far-red flowering lamps with a 24-h photoperiod (24-h); or no supplemental or photoperiodic lighting (Natural). Means sharing a letter are not statistically different by Tukey's honestly significant difference test at $P \leq 0.05$.

$12 \mathrm{~mol} \cdot \mathrm{m}^{-2} \cdot \mathrm{d}^{-1}$ for high-quality plug production (Pramuk and Runkle, 2005; Randall and Lopez, 2014). This insufficient DLI ultimately led to shade avoidance symptoms under PL and natural light conditions, resulting in the excessive stem elongation observed for impatiens and petunia.

One means by which excessive extension growth may be suppressed is through manipulation of the light spectrum. Specifically, blue light has commonly been linked to growth inhibition of bedding plant seedlings (Randall and Lopez, 2014; Wollaeger and
Runkle, 2015). For example, Randall and Lopez (2014) observed shorter stem lengths for snapdragon (Antirrhinum majus) 'Rocket Pink', vinca (Catharanthus roseus) 'Titan Punch', celosia (Celosia argentea var. plumose) 'Fresh Look Gold', impatiens 'Dazzler Blue Pearl', and petunia 'Plush Blue' seedlings grown under LED SL providing 15 to $30 \mu \mathrm{mol} \cdot \mathrm{m}^{-2} \cdot \mathrm{s}^{-1}$ of blue light compared with HPS SL. In our study, gerbera, impatiens, and petunia seedlings displayed less stem elongation under LED compared with HPS SL. This response could be attributed to the slightly greater percentage of blue light emitted from the LED ( $10 \%$ blue) compared with HPS ( $6 \%$ blue) lamps. However, Poel and Runkle (2017) found little difference in the morphology of bedding plant seedlings across multiple species regardless of the spectrum or SL source used. They attributed their contradictory findings with previous research to differences in the contribution of SL to DLI. For example, Poel and Runkle (2017) found that SL provided $20 \%$ to $40 \%$ of the total DLI in their study, whereas the SL treatments used by Randall and Lopez (2014, 
2015) contributed $40 \%$ to $60 \%$ of the total DLI. In our study, SL from both HPS and LED lamps provided $40 \%$ to $55 \%$ of the total DLI. Therefore, based on these results and those of Randall and Lopez (2014, 2015), for SL sources to elicit morphological responses in bedding plant seedlings, such as compact growth, the contribution to the DLI must be substantial (e.g., $>40 \%$ ).

Another reason for the greater stem elongation under HPS compared with LED SL for gerbera, impatiens, and petunia seedlings may be a result of the far-red light $\left(\approx 6 \mu \mathrm{mol} \cdot \mathrm{m}^{-2} \cdot \mathrm{s}^{-1}\right)$ emitted from the HPS lamps. This response is linked directly to the photoreceptor phytochrome, which detects changes in the red:far-red (R:FR) light ratio (Runkle and Heins, 2001). Shade avoidance symptoms such as increased stem elongation and leaf area have been reported as a response to a reduced R:FR ratio (Franklin and Whitelam, 2005; Park and Runkle, 2017; Zhang and Folta, 2012). Thus, the inclusion of the additional far-red light supplied by the HPS lamps reduced the R:FR ratio, and likely contributed to the stem elongation response observed.

Gerbera, impatiens, and petunia seedlings displayed greater shoot dry mass accumulation under HPS_90 compared with both LED SL treatments. Although leaf area data were not collected for gerbera, both impatiens and petunia had the greatest leaf area under HPS_90. Larger leaf area is commonly correlated with increased dry mass accumulation for many plant species because more surface area is available for light interception (Van Ieperen et al., 2012; Wollaeger and Runkle, 2015). Thus, increased dry mass accumulation under HPS SL in our study was likely linked to increased leaf area. Similar to observations with stem elongation and diameter, one reason for the greater leaf area under HPS SL is a lesser percentage of blue light emitted from these lamps. Specifically, under LED SL, leaf expansion may have been suppressed by the greater intensity of blue light emitted from these lamps. Therefore, although the inclusion of blue light does lead to more compact growth, this may ultimately limit the plant's capacity for photosynthetic activity and thus biomass accumulation.

Another factor contributing to the increased biomass and leaf area under HPS SL may have been the inclusion of far-red light. As discussed previously, the reduced R: FR ratio under HPS SL may have contributed to a shade avoidance response of greater leaf area, ultimately leading to increased biomass accumulation resulting from the increased capacity for light interception. In addition, warmer leaf temperatures are commonly associated with HPS lamps because of their emission of radiant heat (Faust and Heins, 1997). This was observed in our study: The average leaf temperature under HPS SL was $\approx 1{ }^{\circ} \mathrm{C}$ greater than under LED SL. Thus, the slightly warmer leaf temperatures under the HPS SL may have contributed to the greater root dry mass, shoot dry mass, and stem diameter observed.
A 24-h photoperiod has been shown previously to be beneficial for tomato (Solanum lycopersicum) seedlings grown in a closed system under sole-source lighting. Specifically, Ohyama et al. (2005) found that the fresh weight, dry weight, and leaf area of tomato 'Momotaro' were $41 \%, 25 \%$, and $64 \%$ greater, respectively, with a $24-\mathrm{h}$ compared with a 16-h photoperiod with an equivalent DLI. However, many studies have also reported physiological disorders and abnormal growth during a 24-h photoperiod (Arthur et al., 1930; Vlahos, 1990; Warrington and Norton, 1991). Although most species in our study showed very few morphological effects as a result of the 24-h photoperiod, impatiens displayed a shorter stem length and smaller leaf area under R:W: FR_24 compared with R:W:FR_16. Although impatiens in our study did not exhibit any physiological disorders, the reduced growth under R:W:FR_24 warrants further research.

The QI provides a means by which to assess seedling quality objectively through the integration of morphological parameters linked to desired attributes (Currey et al., 2013; Randall and Lopez, 2014). In general, greater QI values indicate greater seedling quality. Both the SQ and QI were often greater under LED compared with HPS SL. Although biomass accumulation was often less under LED SL, the shorter stems and larger diameters observed in these SL treatments attributed to sturdier seedlings with greater QI values. In addition, QI values for seedlings under PL were often less than $50 \%$ of what was attained under HPS and LED SL. Much of this reduction in quality was connected to a reduction in root dry mass and shoot dry mass under PL compared with SL. Regardless of the reduced biomass accumulation, leaf area was often larger for impatiens and petunia seedlings under PL compared with SL. In addition to stem elongation, shade avoidance symptoms include larger and thinner leaves (Franklin and Whitelam, 2005; Park and Runkle, 2017; Zhang and Folta, 2012). Thus, seedlings grown under PL were receiving insufficient light intensities for optimal growth, resulting in a shade avoidance response of greater leaf expansion as seedlings attempted to increase light interception. Therefore, for growers interested in using PL for the production of bedding plant seedlings in northern climates, a high-quality crop cannot be produced using solely low-intensity PL during winter months. The additional light supplied by PL $\left(1-2 \mu \mathrm{mol} \cdot \mathrm{m}^{-2} \cdot \mathrm{s}^{-1}\right)$ is insufficient to achieve recommended DLI targets for desirable growth compared with the output from typical SL sources $\left(70-90 \mu \mathrm{mol} \cdot \mathrm{m}^{-2} \cdot \mathrm{s}^{-1}\right)$.

For impatiens, both HPS and LED SL during propagation decreased TTF compared with PL or natural light. Previous studies have shown that a greater propagation DLI generally decreases TTF for both seedlings and cuttings (Hutchinson et al., 2012; Lopez and Runkle, 2008; Oh et al., 2010). For example, Hutchinson et al. (2012) found that
TTF for vegetatively propagated angelonia (Angelonia angustifolia) 'AngelMist White Cloud' and osteospermum (Osteospermum ecklonis) 'Voltage Yellow' was related linearly to the propagation DLI, with a greater DLI leading to earlier flowering at finish. Similarly, Lopez and Runkle (2008) found that TTF decreased for cuttings of petunia 'Tiny Tunia Violet' and 'Supertunia Mini Purple' as the propagation DLI increased from 1.4 to $10.7 \mathrm{~mol} \cdot \mathrm{m}^{-2} \cdot \mathrm{d}^{-1}$. Species that flower earlier when grown under greater light environments exhibit a facultative irradiance response and generally develop fewer nodes before flowering as a result (Erwin et al., 2017). Differences in TTF between SL treatments for petunia were also observed, with seedlings grown under HPS SL flowering earlier compared with LED SL. This flowering response was likely tied to observations made previously regarding seedling quality under HPS compared with LED SL. Specifically, the increased leaf area, leaf number, and shoot dry mass observed under HPS compared with LED SL likely contributed to the establishment and earlier flowering of these seedlings. In addition, for species with a long-day photoperiodic response, far-red light has been shown to affect the promotion of flowering significantly (Downs and Thomas, 1982; Park and Runkle, 2017). Thus, the reduced R:FR under HPS compared with LED SL likely contributed to earlier flowering for petunia. Although a decrease in TTF may be desired by some growers, the finishing container size ultimately dictates whether continued vegetative growth or earlier flowering is preferred (Hutchinson et al., 2012; Mattson and Erwin, 2005). For example, in our study, both impatiens and petunia displayed smaller widths and fewer buds at flowering when TTF was reduced.

Petunia seedlings grown under a 16-h photoperiod provided by $\mathrm{R}: \mathrm{W}: \mathrm{FR}$ lamps flowered earlier than those under LED_70, LED_90, R:W_16, and natural light. For petunia, the response to far-red light appears to impact flower induction during propagation, whereas impatiens and gerbera, both lacking a long-day photoperiodic response, were unaffected by the inclusion of far-red light. Based on the results from our study, growers interested in using LED PL to reduce petunia TTF should ensure that far-red light is included in the spectrum emitted, because a long-day photoperiod without far-red light (R:W_16) did not promote flowering. However, providing far-red light with a 24-h photoperiod (R:W:FR_24) was inhibitory to flowering. With photoperiodic responses dictated by the length of a dark period (Thomas and Vince-Prue, 1997), this response is expected, as plants with a 24 -h photoperiod were unable to perceive night length.

SL using an instantaneous threshold has great potential for energy savings. In our study, both HPS and LED threshold SL reduced the operating hours over an experimental replication by 45 to $128 \mathrm{~h}$ (Table 1 ). With the quality of seedlings produced under threshold SL being generally equivalent to 
those produced under continuous SL with a 16-h photoperiod, growers can achieve energy savings. However, although very few differences were observed between LED_70 and LED_90, the use of threshold SL with HPS lamps (HPS_90) resulted in increased leaf area and shoot dry mass for impatiens and petunia seedlings compared with HPS_70. The physiological mechanism by which these increases occurred remains uncertain, and future research is required to understand this response fully.

\section{Conclusions}

The results from our study quantify the benefits of SL on both the quality and subsequent flowering of bedding plant seedlings. Although PL may present a limited benefit of reducing TTF for species with a long-day photoperiodic response, seedlings produced under PL were generally of lower quality because these light sources did not increase the DLI meaningfully. Regarding SL, one area of significant interest to the industry is the use of an instantaneous threshold to reduce energy costs. Based on our findings, seedlings produced under HPS or LED threshold SL were of equal or greater quality to those produced under continuous SL with a 16-h photoperiod. Thus, growers looking to reduce SL energy costs may be interested in using this technology to reduce lamp operating hours. In addition, species-specific responses to SL provided by LED and HPS lamps are an important consideration that warrant further research.

\section{Literature Cited}

Arthur, J.W., J.D. Guthrie, and J.M. Newell. 1930. Some effects of artificial climates on the growth and chemical composition of plants. Amer. J. Bot. 17:416-482.

Both, A.J., B. Bugbee, C. Kubota, R.G. Lopez, C. Mitchell, E.S. Runkle, and C. Wallace. 2017. Proposed product label for electric lamps used in the plant sciences. HortTechnology 27:544-549.

Craig, D.S. and E.S. Runkle. 2012. Using LEDs to quantify the effect of the red to far-red ratio of night-interruption lighting on flowering of photoperiodic crops. Acta Hort. 956:179186.

Currey, C.J., A.P. Torres, R.G. Lopez, and D.F. Jacobs. 2013. The quality index: A new tool for integrating quantitative measurements to assess quality of young floriculture plants. Acta Hort. 1000:385-391.
Downs, R.J. and J.F. Thomas. 1982. Phytochrome regulation of flowering in the long-day plant, Hyoscyamus niger. Plant Physiol. 70:898-900.

Erwin, J., N. Mattson, and R. Warner. 2017. Light effects on bedding plants, p. 119-134. In: R. Lopez and E. Runkle (eds.). Light management in controlled environments. Meister Media Worldwide, Willoughby, $\mathrm{OH}$.

Faust, J.E. and R.D. Heins. 1997. Quantifying the influence of high-pressure sodium lighting on shoot-tip temperature. Acta Hort. 418:85-91.

Franklin, K.A. 2008. Shade avoidance. New Phytol. 179:930-944.

Franklin, K.A. and G.C. Whitelam. 2005. Phytochromes and shade-avoidance responses in plants. Ann. Bot. 96:169-175.

Hernández, R. and C. Kubota. 2016. Physiological responses of cucumber seedlings under different blue and red photon flux ratios using LEDs. Environ. Expt. Bot. 121:66-74.

Hutchinson, V.A., C.J. Currey, and R.G. Lopez. 2012. Photosynthetic daily light integral during root development influences subsequent growth and development of several herbaceous annual bedding plants. HortScience 47:856860.

Lopez, R., C. Currey, and E. Runkle. 2017. Light and young plants, p. 109-118. In: R. Lopez and E. Runkle (eds.). Light management in controlled environments. Meister Media Worldwide, Willoughby, $\mathrm{OH}$.

Lopez, R.G. and E.S. Runkle. 2008. Photosynthetic daily light integral during propagation influences rooting and growth of cuttings and subsequent development of New Guinea impatiens and petunia. HortScience 43:2052-2059.

Massa, G.D., H. Kim, R.M. Wheeler, and C.A. Mitchell. 2008. Plant productivity in response to LED lighting. HortScience 43:1951-1956.

Mattson, N.S. and J.E. Erwin. 2005. The impact of photoperiod and irradiance on flowering of several herbaceous ornamentals. Scientia Hort. 104:275-292.

Morrow, R.C. 2008. LED lighting in horticulture. HortScience 43:1947-1950.

Nelson, J.A. and B. Bugbee. 2014. Economic analysis of greenhouse lighting: Light emitting diodes vs. high intensity discharge fixtures. PLoS One 9: e99010, doi: 10.1371/journal.pone.0099010.

Oh, W., E.S. Runkle, and R.M. Warner. 2010. Timing and duration of supplemental lighting during the seedling stage influence quality and flowering in petunia and pansy. HortScience 45:1332-1337.

Ohyama, K., K. Manabe, Y. Omura, T. Kozai, and C. Kubota. 2005. Potential use of a 24-hour photoperiod (continuous light) with altering air temperature for production of tomato plug transplants in a closed system. HortScience 40:374-377.

Park, Y. and E.S. Runkle. 2017. Far-red radiation promotes growth of seedlings by increasing leaf expansion and whole-plant net assimilation. Environ. Expt. Bot. 136:41-49.
Poel, B.R. and E.S. Runkle. 2017. Seedling growth is similar under supplemental greenhouse lighting from high-pressure sodium lamps or lightemitting diodes. HortScience 52:388-394.

Pramuk, L.A. and E.S. Runkle. 2005. Photosynthetic daily light integral during the seedling stage influences subsequent growth and flowering of Celosia, Impatiens, Salvia, Tagetes, and Viola. HortScience 40:1336-1339.

Randall, W.C. and R.G. Lopez. 2014. Comparison of supplemental lighting from high-pressure sodium lamps and light-emitting diodes during bedding plant seedling production. HortScience 49:589-595.

Randall, W.C. and R.G. Lopez. 2015. Comparison of bedding plant seedlings grown under solesource light-emitting diodes (LEDs) and greenhouse supplemental lighting from LEDs and high-pressure sodium lamps. HortScience 50: 705-713.

Runkle, E.S. and A.J. Both. 2017. Delivering longday lighting: Technology options and costs, p. 91-99. In: R. Lopez and E. Runkle (eds.). Light management in controlled environments. Meister Media Worldwide, Willoughby, $\mathrm{OH}$.

Runkle, E.S. and R.D. Heins. 2001. Specific functions of red, far red, and blue light in flowering and stem extension of long-day plants. J. Amer. Soc. Hort. Sci. 126:275-282.

Sparks, B. 2016. Micandy gardens uses new technology and energy efficiency to stay ahead of the curve. 28 Aug. 2018. <https://www. greenhousegrower.com/management/ micandygardens-uses-new-technology-and-energyefficiency-to-stay-ahead-of-the-curve/>.

Styer, C. 2003. Propagating seed crops, p. 151163. In: D. Hamrick (ed.). Ball redbook crop production: Volume two. 17th ed. Ball Publishing, Batavia, IL.

Thomas, B. and D. Vince-Prue. 1997. Photoperiodism in plants. 2nd ed. Academic Press, London, UK.

Van Ieperen, W., A. Savvides, and D. Fanourakis. 2012. Red and blue light effects during growth on hydraulic and stomatal conductance in leaves of young cucumber plants. Acta Hort. 956:223-230.

Vlahos, J.C. 1990. Temperature and irradiance influence growth and development of three cultivars of Achimenes. HortScience 25:1597-1598.

Wallace, C. and A.J. Both. 2016. Evaluating operating characteristics of light sources for horticultural applications. Acta Hort. 1134:435-444.

Warrington, I.J. and R.A. Norton. 1991. An evaluation of plant growth and development under various daily quantum integrals. J. Amer. Soc. Hort. Sci. 116:544-551.

Wollaeger, H.M. and E.S. Runkle. 2015. Growth and acclimation of impatiens, salvia, petunia, and tomato seedlings to blue and red light. HortScience 50:522-529.

Zhang, T. and K. Folta. 2012. Green light signaling and adaptive response. Plant Signal. Behav. $7: 1-4$. 